\title{
Potential for Colonization and Ochratoxin A Production of Aspergillus Carbonarius in Different Grape Varieties
}

\author{
Bruna Dachery (I), Sheila Canossa (I), Emilli Keller Bol (I), Débora \\ Senger (I), Flávio Veras (I), Vitor Manfroi (I), Juliane welke (I) \\ (I) UFRGS - Universidade Federal do Rio Grande do Sul (Avenida Bento Gonçalves, 9500, \\ CEP 91501-970 Porto Alegre, RS)
}

\section{Resumo}

Aspergillus carbonarius has been identified as the main fungus responsable to produce ochratoxin A (OTA) in grapes cultived in various countries. OTA is well-know nephrotoxic agent and has been associated to the incidence of tumors of the urinary organs. The properties immunosuppressive, teratogenic and carcinogenic have also been reported. The International Agency of Research on Cancer has classified OTA in group 2B, as a possible human carcinogenic. The presence of $\mathrm{A}$. carbonarius in grapes depends on $\mathrm{pH}$, water activity and temperature. Beyond these factors, the grape variety can play an important role in the levels of OTA in grapes and derivatives, including juice, wine and dried grapes. The objective of this work was to evaluate the potential of colonization and ability to produce OTA of A. carbonarius in three grape varieties (Cabernet Sauvignon, Isabel e Italy). These grapes were produced in Serra Gaúcha region of Rio Grande do Sul state, Brasil in the 2014 crop. Only grapes not physically damaged were used in this study. The strain of A. carbonarius used in this work was isolated from naturally infected grapes and the toxigenic potential was previously confirmed using thin layer chromatography with charge coupled device. A conidial suspension it was applied to the grapes that were maintained at $25^{\circ} \mathrm{C}$ during 12 days. Isabel and Italy grapes showed visible fungal growth and OTA only after $9^{\circ}$ day at $25^{\circ} \mathrm{C}$. Cabernet Sauvignon was the variety more resistente to the

\footnotetext{
Referência:

Bruna Dachery, Sheila Canossa, Emilli Keller Bol, Débora Senger, Flávio Veras, Vitor Manfroi, Juliane welke.Potential for Colonization and Ochratoxin A Production of Aspergillus Carbonarius in Different Grape Varieties. In: Anais do 12ㅇ Congresso Latinoamericano de Microbiologia e Higiene de Alimentos - MICROAL 2014 [= Blucher Food Science Proceedings, num.1, vol.1]. São Paulo: Editora Blucher, 2014. 
colonization by A. carbonarius, including that after 12 days OTA was not produced by this fungus. After 12 days at $25^{\circ} \mathrm{C}$, the damage caused by $\mathrm{A}$. carbonarius in Italy grape occuped all grape. In Cabernet Sauvignon, a little damage (A. carbonarius and subsequent OTA production depends on the variety of grape. This fact may be related to the thickness of the grape skin, because Cabernet Sauvignon has the most rigid skin and was more resistant to fungal contamination. These observations are important to plan actions to minimize fungal contamination in the most susceptible grapes.

Palavras-Chave: mycotoxin, grape, storage Agência de Fomento: CNPq, FAPERGS and CAPES 